\title{
Antibody to hepatitis B surface antigen in haemophiliacs on long-term therapy with Scottish factor VIII
}

\author{
C. J. BURRELL, S. H. BLACK, AND D. M. RAMSAY \\ From the Hepatitis Reference Laboratory, Department of Bacteriology, Edinburgh Medical School, \\ Edinburgh, and the Department of Haematology, Royal Infirmary, Edinburgh, UK
}

SUMMARY Thirty-five patients with haemophilia A were studied clinically and serologically between 1971-2 and 1975-6 for evidence of hepatitis B infection. One patient suffered from clinical hepatitis B, and a further eight patients showed antibody reponses to hepatitis B surface antigen ( $\mathrm{HBsAg}$ ) consistent with exposure to HBsAg during this period. No evidence for HBsAg exposure was found in 14 patients, while the remaining 12 patients had high titres of antibody to HBsAg at both times and no inferences could be drawn about HBsAg exposure. All patients had received exclusively replacement factor VIII material prepared locally from HBsAg-screened voluntary Scottish blood donations. From the details of the therapy given we calculated that the rate of HBsAg seroconversion in these patients represented about $0 \cdot 3 \mathrm{HBs} A g$-containing donations/1000 donations.

The presence of hepatitis B surface antigen (HBsAg) or the development of antibody to hepatitis B core antigen (anti-HBc) or to $\mathrm{HBsAg}$ (anti-HBs) are currently the most reliable serological markers of hepatitis B virus (HBV) infection (Hoofnagle et al., 1975). The first two of these reactions almost invariably indicate ongoing or recent virus replication. The development of the more long-lasting antiHBs (or a significant rise in titre) may indicate either infection or active immunisation with HBsAg.

Surveys of the prevalence of anti-HBs in multiply transfused haemophiliacs have confirmed the high rates of exposure to $\mathrm{HBsAg}$ in such patients (Peterson et al., 1973; Burrell et al., 1974; Islam and Banatvala, 1976), although they rarely develop clinical hepatitis (Biggs, 1974). Universal blood donor screening for $\mathrm{HBsAg}$ has substantially reduced but not eliminated post-transfusion hepatitis $B$ infection. For example, in a study of recipients of whole blood transfusion after screening for $\mathrm{HBsAg}$ by radioimmunoassay $4 \cdot 7 / 1000$ tested volunteer donations produced serological evidence of $\mathrm{HBsAg}$ exposure (Goldfield et al., 1975). The continuing risk of HBV infection for haemophiliacs is more difficult to assess.

In a previous study (Burrell et al., 1974) we reported that $17(36 \cdot 9 \%)$ of 46 haemophiliacs attend-

Received for publication 19 October 1977 ing the Edinburgh Haemophilia Reference Centre in 1972 were positive for anti-HBs using a radioimmunoprecipitation assay. Those who most often required treatment showed the highest antibody prevalence (15 $(55.5 \%)$ positive out of 27$)$. Patients attending the centre receive only replacement material prepared locally from HBsAg-tested volunteer blood donations. HBsAg-positive donations, which in different Scottish regions range from $0 \cdot 2-1 \cdot 25 / 1000$ donations (R. Hopkins, personal communication) are excluded. On the other hand, anti-HBs-positive donations $(29 / 1000$ donations by radioimmunoprecipitation for the Edinburgh region (Burrell et al., 1977)) are not excluded. This situation has provided a unique opportunity to study hepatitis B seroconversion rates in patients coming into contact with fractions from large numbers of volunteer plasma donations, prepared within one centre, since the institution of universal HBsAg screening.

We report a study of selected haemophiliacs over the period 1971-2 and 1975-6 with respect to the development of anti-HBs and an attempt to relate the findings to the type and frequency of replacement factor VIII therapy during this period.

\section{Patients and methods}

Thirty-five haemophilia A patients were included in the survey. A serum sample was taken from each 
between April 1971 and June 1972 and again between July 1975 and March 1976 and stored at $-20^{\circ} \mathrm{C}$. The sera were examined at the same time (1976) for HBsAg by reverse passive haemagglutination (RPHA) and for antibody to $\mathrm{HBsAg}$ (anti-HBs) by radioimmunoprecipitation (Burrell et al., 1974). During this period only one patient suffered from clinical HBsAg-positive hepatitis and subsequently seroconverted to anti-HBs positive (see below).

Liver function tests carried out at irregular intervals on most of the patients found no evidence of additional acute infections. All patients except three received varying amounts of replacement therapy during the period. This was given as cryoprecipitate (Pool et al., 1964), prepared by the Blood Transfusion Service, Edinburgh, from local HBsAgtested donations, and as anti-haemophiliac factor (AHF (Blömback, 1958)) or factor VIII concentrate (Newman et al., 1971; James and Wickerhauser, 1972) prepared by the Protein Fractionation Centre of the Scottish National Blood Transfusion Service from donations that were $\mathrm{HBsAg}$ tested and forwarded by the various Scottish Blood Transfusion Centres.

HBsAg testing was done initially by countercurrent immunoelectrophoresis and more recently by haemagglutination inhibition (HAI) (Hopkins and Das, 1973), RPHA (Wellcome Laboratories), or radioimmunoassay (RIA) (Ausria).

\section{Results}

At both sampling times all 35 patients were negative for HBsAg by RPHA and $20(57 \%)$ of them were anti-HBs positive. Twelve patients remained antiHBs positive with unchanging high titres during the study period. No inferences could be made about the effect of therapy on their antibody state. The remaining 23 patients could be grouped as (1) Anti-HBs positive in 1971-2 and negative in 1975-6, (2) AntiHBs negative on both occasions, (3) Anti-HBs negative in 1971-2 and positive in 1975-6, (4) AntiHBs positive on both occasions with a hundredfold or greater increase in antibody titre between the two sampling periods.

In interpreting these findings in terms of exposure to $\mathrm{HBsAg}$ it seemed possible that patients in group (2) (negative $\rightarrow$ negative) might have developed and subsequently lost short-lived anti-HBs during the study period. One of eight sera from six of these patients taken at intervening times was indeed found to be anti-HBs positive. This patient was therefore considered to have been exposed to HBsAg. Possibly the anti-HBs detected in some patients may have been passive antibody present in the therapeutic material administered. While not totally excluded, this was considered unlikely since, with one exception, the antibody levels seen above were 10 to 1000 times higher than those that occur after administration of high-titre anti-HBs immune globulin for HBV prophylaxis (unpublished observations). Inapparent exposure to $\mathrm{HBsAg}$, unrelated to parenteral therapy, was also considered unlikely, since none of the patients had life-styles known to be associated with a high risk of hepatitis B infection. No seroconversions have occurred among about 60 clinical and laboratory staff studied over the same period, and although these cannot be considered strictly comparable controls their non-parenteral infection rate seems low. Table 1 shows the composition of the various groups and their exposure to $\mathrm{HBsAg}$.

Three of the 14 patients without evidence of exposure to HBsAg had not required any therapy during the study period. They were excluded from further study. The therapy given to the remaining nine seroconverters and 11 patients without evidence of exposure was then examined in detail (Table 2). Records were available of all preparations administered (including batch numbers for AHF and factor VIII concentrates), making it possible to allow for individual patients receiving repeated treatment with one batch and the use of one batch for more than one patient. There was no obvious association between seroconversion and any one form of therapy.

Since the cryoprecipitate units were prepared from single donations and the AHF and factor VIII concentrate from pools of about 30 and 800 donations respectively we could calculate the total number of donation exposures for each patient. After allowing for 13 batches of AHF and nine batches of factor VIII concentrate that were given to more than one patient (usually two), we calculated that the two groups of patients combined had received 9256 different batches of cryoprecipitate, 115 different batches of AHF (3450 donations), and 27 different batches of factor VIII concentrate (21 600 donations), representing exposure to a total of about 34300 donations. Since there were nine seroconversions among recipients of this material probably at least nine of these donations contained $\mathrm{HBsAg}$ - that is, one positive donation in every 3800 , or 0.3 positive donations $/ 1000$ donations.

\section{Discussion}

The anti-HBs seroconversion events recorded here may have resulted after infection with hepatitis B virus or after active immunisation with HBsAgpositive material. Serological distinction between these two alternatives (for example, by regular testing for $\mathrm{HBsAg}$ and anti-HBc) was not possible. Patients 
Table 1 Classification of patients according to changes in anti-HBs reactivity

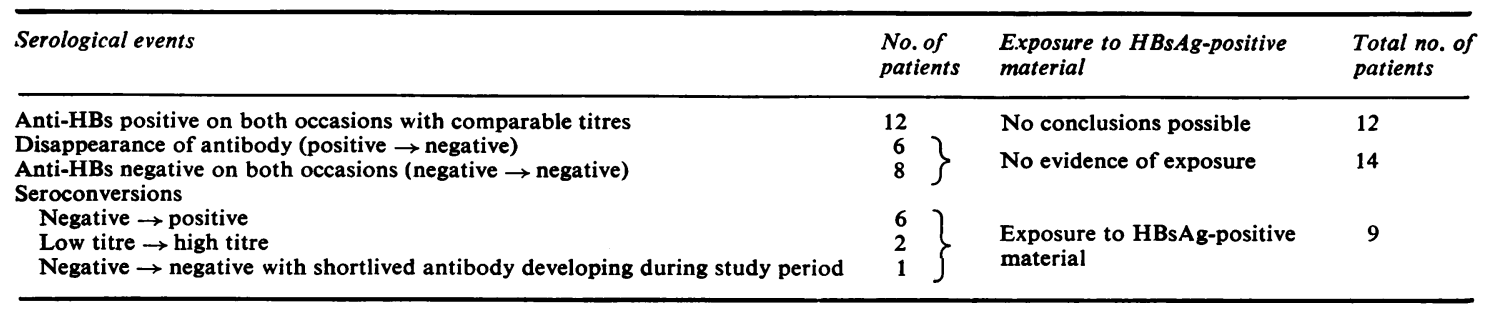

Table 2 Therapy received by groups indicated during period of study

\begin{tabular}{|c|c|c|c|c|c|c|}
\hline \multirow{2}{*}{$\begin{array}{l}\text { No. of patients } \\
\text { who } \\
\text { seroconverted }\end{array}$} & \multirow{2}{*}{$\begin{array}{l}\text { No.of } \\
\text { cryoprecipitate } \\
\text { donations }\end{array}$} & \multicolumn{2}{|l|}{$A H F$} & \multicolumn{2}{|c|}{ Factor VIII concentrate } & \multirow{2}{*}{$\begin{array}{l}\text { Total no. of } \\
\text { donation-exposures }\end{array}$} \\
\hline & & $\begin{array}{l}\text { No. of different } \\
\text { batches }\end{array}$ & $\begin{array}{l}\text { Approx. no. of } \\
\text { donations involved }\end{array}$ & $\begin{array}{l}\text { No. of different } \\
\text { batches }\end{array}$ & $\begin{array}{l}\text { Approx. no. of } \\
\text { donations }\end{array}$ & \\
\hline $\begin{array}{l}1 \\
2 * \\
3 \\
4 \\
5 \\
6 \\
7 \\
8 \\
9\end{array}$ & $\begin{array}{r}15 \\
1523 \\
398 \\
12 \\
675 \\
125 \\
980 \\
1609 \\
106\end{array}$ & $\begin{array}{r}-6 \\
8 \\
1 \\
20 \\
12 \\
39 \\
1\end{array}$ & $\begin{array}{r}-\overline{180} \\
240 \\
30 \\
600 \\
360 \\
1170 \\
30\end{array}$ & $\begin{array}{l}- \\
\bar{Z} \\
\frac{4}{4} \\
\frac{6}{22}\end{array}$ & $\begin{array}{r}\bar{z} \\
\overline{-} \\
3200 \\
\overline{4} \overline{-} \\
17600 \\
-\end{array}$ & $\begin{array}{r}15 \\
1703 \\
638 \\
42 \\
4475 \\
125 \\
6140 \\
20379 \\
136\end{array}$ \\
\hline Total & 5443 & 87 & 2610 & 32 & 25600 & 33653 \\
\hline \multicolumn{7}{|c|}{$\begin{array}{l}\text { Patients without } \\
\text { evidence of exposure }\end{array}$} \\
\hline $\begin{array}{l}1 \\
2\end{array}$ & $\begin{array}{l}377 \\
512\end{array}$ & $-\overline{1}$ & $\overline{30}$ & - & $=$ & $\begin{array}{c}377 \\
542\end{array}$ \\
\hline 3 & 1009 & - & - & $\overline{1}$ & 800 & 1809 \\
\hline 4 & 154 & - & - & - & - & 154 \\
\hline 5 & 423 & 32 & 960 & 3 & 2400 & 3783 \\
\hline 6 & 165 & 2 & 60 & - & - & 225 \\
\hline 7 & 12 & - & - & - & - & 12 \\
\hline 8 & 46 & - & - & - & - & 46 \\
\hline 9 & 30 & 3 & 90 & - & - & 120 \\
\hline 10 & 505 & 3 & 90 & - & - & 595 \\
\hline 11 & 580 & - & - & - & - & 580 \\
\hline Total & 3813 & 41 & 1230 & 4 & 3200 & 8243 \\
\hline
\end{tabular}

*HBsAg positive 29 January 1974; negative 14 September 1975.

without evidence of exposure may include poor antibody responders or individuals with a short-lived anti-HBs response after contact with positive material. Indeed, the disappearance of detectable anti-HBs between the two sampling times in six patients described here provided clear evidence that such antibody need not persist for life and that surveys of anti-HBs prevalence at one time point will not identify all those who have had HBV infection.

In considering our findings we also noted the following factors.

(1) Our figure of $0.3 \mathrm{HBsAg}$ positive donations/ 1000 after $\mathrm{HBsAg}$ testing may be lower than the true rate of HBsAg-positive single donations since $(a)$ patients who seroconverted may have received more than one positive unit, (b) positive batches of AHF and factor VIII concentrate may have contained more than one positive donation, and (c) the coexistence of anti-HBs in plasma pools containing $\mathrm{HBsAg}$ used to prepare AHF or factor VIII concentrate may have partially neutralised the infectivity (but not necessarily immunogenicity) of the preparation.

(2) The degree of dilution of the HBsAg in one positive donation will have varied significantly according to whether cryoprecipitate (pool size $=1$ ) or factor VIII concentrate (pool size $=800$ ) was used and according to the variable extent of selective concentration or removal of HBsAg and infectious virus during fractionation of the different preparations. Thus the quantities of viral material administered may not be strictly comparable to whole blood transfusion. 
(3) Many patients in this survey received repeated treatments with the same batch of material separated by hours, days, or weeks. HBV infection might be favoured by one large dose whereas active immunisation could be favoured by repeated antigenic stimuli of adequate size. We could not examine the effects of these factors on seroconversion rates.

A Danish study of 36 children with haemophilia A or B receiving replacement therapy from various sources showed serological evidence for 16 exposures to HBsAg in the period 1970-6 (Holsteen et al., 1977). This represented an overall rate of $1.25 \mathrm{HBsAg}$ positive donations/1000 donation exposures. Calculations suggested that both Danish volunteer and commercial single donor preparations carried a similar risk, which was increased with the use of pooled donor material from either source. However, the inclusion of haemophilia B patients in the Danish study and the use of preparations from several sources in some of the patients have introduced additional variables to those in our survey.

Finally, our findings should not be extrapolated to represent the true rate of $\mathrm{HBV}$ infection in the donor population after HBsAg screening. However, they should provide a guide to the likelihood of seroconversion to anti-HBs positivity after factor VIII replacement from similar defined sources and a basis for comparison of this material with commercial factor VIII preparations.

We thank Dr S. H. Davies, Department of Haematology, Professor B. P. Marmion, Department of Bacteriology, and Mr J. G. Watt, Protein Fractionation Centre, Scottish National Blood Transfusion Service, for their encouragement in this work and helpful criticism of the manuscript.

\section{References}

Biggs, R. (1974). Jaundice and antibodies directed against Factors VIII and IX in patients treated for haemophilia or Christmas disease in the United Kingdom. British Journal of Haematology, 26, 313-329.

Blömback, M. (1958). Purification of antihemophilic globulin. I. Some studies on the stability of the anti- hemophilic globulin activity in fraction I-O and a method for its partial separation from fibrinogen. Arkiv för Kemi, 12, 387-396.

Burrell, C. J., Parker, A. C., Ramsay, D. M., and Proudfoot, E. (1974). Antibody to hepatitis B antigen in haemophiliacs and their household contacts. Journal of Clinical Pathology, 27, 323-325.

Burrell, C. J., Tonkin, R. W., Proudfoot, E., Leadbetter, G., Cowan, P., Lockerbie, L., Gore, S., Lutz, W., and Marmion, B. P. (1977). Prevalence of antibody to hepatitis B surface antigen among staff in an Edinburgh hospital. Journal of Hygiene, 78, 57-68.

Goldfield, M., Black, H. C., Bill, J., Srihongse, S., and Pizzuti, W. (1975). The consequences of administering blood pretested for HBsAg by third generation techniques: a progress report. American Journal of the Medical Sciences, 270, 335-342.

Holsteen, V., Skinhoj, P., and Cohn, J. (1977). Hepatitis, type B in haemophiliacs: Relation to the source of clotting factor concentrates. Scandinavian Journal of Haematology, 18, 214-218.

Hoofnagle, J. H., Gerety, R. J., and Barker, L. F. (1975). Hepatitis B core antigen and antibody. Developments in Biological Standardization, 30, 175-185.

Hopkins, R., and Das, P. C. (1973). A tanned cell haemagglutination test for the detection of hepatitis-associatedantigen (Au-Ag) and antibody (anti-Au). British Journal of Haematology, 25, 619-629.

Islam, M. N., and Banatvala, J. E. (1976). The prevalence of hepatitis-B antigen (HBsAg) and its antibody (antiHBs) among London hemophiliacs and blood donors from London and two tropical areas. Transfusion, 16, 237-241.

James, H. L., and Wickerhauser, M. (1972). Development of large-scale fractionation methods. III. Preparation of a factor VIII concentrate of intermediate purity. Vox Sanguinis, 23, 402-412.

Newman, J., Johnson, A. J., Karpatkin, M. H., and Puszkin, S. (1971). Methods for the production of clinically effective intermediate- and high-purity factorVIII concentrates. British Journal of Haematology, 21, 1-20.

Peterson, M. R., Barker, L. F., and Schade, D. S. (1973). Detection of antibody to hepatitis-associated-antigen in hemophilia patients and in voluntary blood donors. Vox Sanguinis, 24, 66-75.

Pool, J. G., Hershgold, E. J., and Pappenhagen, A. R. (1964). High potency antihaemophilic factor concentrate prepared from cryoglobulin precipitate. Nature, 203, 312 . 